\title{
INTEGRATION OF ARCHITECTURAL AND STRUCTURAL ASPECTS THROUGH THE DESIGN PROCESS: INDIVIDUAL RESIDENTIAL BUILDING
}

\author{
DOI: 10.18485/arh_pt.2020.7.ch25
}

\author{
_ Dimitar Papasterevski \\ PhD, Assistant Professor, Faculty of Architecture, Ss Cyril \\ and Methodius University, bul. Partizanski odredi 24, Skopje, \\ R. of Macedonia, papasterevski.dimitar@arh.ukim.edu.mk
}

\author{
_ Toni Arangjelovski \\ PhD, Associated Professor, Faculty of Civil Engineering, Ss Cyril \\ and Methodius University, bul. Partizanski odredi 24, Skopje, \\ R. of Macedonia, arangelovskitoni@gf.ukim.edu.mk
}

\section{ABSTRACT}

Louis Sullivan's aesthetic credo "form follows function", has become fundamental to the modernist architectural movement. From today's point of view, the relations between form and function have changed so that sometimes structure can follow form, which at the same time implies the established of a new fundamental principle that would sound like "structure ever follows form".

The paper tends to develop a framework for integrating architectural and structural design in order to achieve a harmonious coexistence between architectural technology and arts. Traditionally, through the process of developing the architectural idea in the preliminary design phase, architects are more concerned with form, composition, function and aesthetics; however, the structural properties of the distribution of the load-bearing elements are not taken into consideration at this stage. Our collaborative experience as an architect and civil engineer suggests a new approach to developing architectural projects by integrating the structural layout of elements at the earliest stage in conceptual design development.

Through an example of our author project of a realised individual residential building, we will illustrate the exploration of these aspects. The load-bearing structure is a reinforced concrete skeletal system that defines space that we can call "generic space". The frame itself is specific and has qualities that determine the architecture for a long time. Finally, we proposed a framework for achieving a successful integration to evolve an architecturally pleasing and structurally efficient building. Architecture, as a successful creative product, can only be delivered within this process developed through the balance and harmony of all elements and actors as a whole.

KEYWORDS _ Integration, frame, structural, generic space

\section{INTRODUCTION}

In the work of real architecture, the idea that architecture and structure should create a homogeneous unit is the crucial research in this paper, where the aesthetic is often an outcome in the process of integration of function, structure and other architectural aspects (scale, volume, space, detail, etc.). The harmonious coexistence between technology and art can be achieved if the structural 
system is not an obstacle to perceive the work and the architectonic shape create a logical structural solution. The paper opens the question of the different forms of relationship between architects and structural engineers through historical periods, which as such re-emerges even today. Unfortunately, the evolution of master-builder in the modern sense of the word split that overall creative responsibility to different specialists, namely, the architect, to see to the planning and aesthetics and the engineers to see to the strength, stiffness and functioning of the building. This unnatural separation of roles is responsible for any discrepancies between the form and aesthetics on one hand and the function and technology on the other, which can be explained through various architectural theories. The choice of the optimal structure for the building is the essential mind creation of the structural engineer for a given architectural form of a building, considering contemporary principles through the process of the integrated structural design.

The concept of integration of structural function with the architectural form, with all portions mutually interacting to achieve the full expression of architectural elements, will be considered on the example of an author's architectural project for an individual residential building. Orthogonal reinforced concrete simple flat slab structural system integrates well within the prismatic architectural form, which defines space that we can call "generic space". The frame itself is specific and has qualities that determine the house for a long time, the concept of dwellings that would enable the modification of the interior space for the functional requirements of the next generations, without disturbing the aesthetic value and quality of the architectural form. Our collaborative experience as an architect and civil engineer suggests a new approach to developing architectural projects by integrating the structural layout of elements at the earliest stage in conceptual design development.

\section{THE RELATIONSHIP BETWEEN ARCHITECTS AND STRUCTURAL ENGINEERS}

The question of form and structure is an essential part of architectural history. From the "tectonic unity" of the physical environment in the given local socio-economic contexts to the growing differentiation and specialization of the modern age, we see a dramatic change both in the generating of architecture and in the role of participants and actors in architectural production (Frampton, 1995; Rapoport, 1969).

Amos Rapoport in his anthological work "House Form and Culture" singles out the sequences of the way the constructed form is produced in the pre-modern and modern age (Rapoport, 1969): in "primitive" communities when knowledge is diffused to all and everyone is responsible for the built form which consists of several construction types; in vernacular communities, the experience is detailed into certain groups but in the context of shared values and accepted hierarchical order in a more significant but still a limited number of constructed types; the modern age is marked by growing complexity and differentiation, the built environment consists of original creations that are shaped and constructed by an increasingly branched team of specialists.

In the pre-industrial age, the architecture was created by satisfying the structural requirements of the building, and the relationship between the architect and the engineer was very close, it was practically the same individual, the master-builder, with their aesthetic creativity on the one hand and their technical and management excellence on the other. The traditional role of master-builder began to change with the increased sophistication of technologies in the nineteenth century, especially in its second half, from the discovery of reinforced concrete was a "new" structural material, capable of producing durable and fire-resistant skeletal frames, and thus buildings with a "free plan" interior without structural walls. This required specialisation and those who specialised in these areas of technology were to become the Civil Engineers, later to be even more specialised as Structural Engineers. The buildings, on the other hand, required better and more sophisticated control of the internal environment, services and facilities. From that moment, the relationship between architects and engineers will range from confrontation during the nineteenth century to closer collaboration in the mid-twentieth century and today. In early modernism, architecture became more dependent on the new structural technologies of the twentieth century, as well as on the skills and expertise of 
engineers. The master-builder, as a single person, could no longer master all these specialised fields of technology. So he was gradually forced to take a new role and a new name - the contemporary "architect" who takes the lead in coordinating all aspects of planning and technology while being primarily responsible for the aesthetic quality of a building project. Architects who supported early modernism were interested in the tectonics of architectural buildings, which meant the inevitable close collaboration with engineers, often treating their contribution to the design process as less crucial. Collaboration between architects and engineers are closer, although, moreover, architects remain to be regarded as masters in the design process, treating the remaining designers involved as mere technicians. The emergence of individual engineers in whose works can recognise high architectural qualities is also a feature of this period as a new concept of engineer/architect. The complexity of architectural projects nowadays has led to certain groups of engineers and architects establishing a completely different way of working, working in the design teams, something that requires the joint orchestrated work of all participants, establishing highly cooperative relationships and standards. The building profession as a group is beginning to recognise the need to correct this strange architect-engineer dichotomy through a fresh re-evaluation of the essence of the design itself. Aesthetics and technology need to be reunited again by replacing the single person master-builder with the team of specialists working together in a complementary spirit to create the right solution, sociologically, aesthetically and technologically.

\section{STRUCTURAL FUNCTION AND ARCHITECTURAL FORM}

The harmonious coexistence between technology and art can be achieved in creating the architectural form while respecting the laws of statics, which means active cooperation between architects and civil engineers. Various architectural theories have been developed dealing with the aesthetics of architectural form and related directly to the expression of structural function. One of the most important is Schopenhauer's Theory of Statics, based on the axiom that the single and continuously recurring theme of architecture; the issues of form, symmetry and proportion can be explored solely in terms of the aspect of structure: loads and support. The form must express the struggle of forces to achieve equilibrium; every architectural element must carry its load (Korab-Karpowicz, 2011).

Christian Norberg Schulz, in his work Intentions in Architecture, divides forms into two categories deriving from the two interconnected systems of construction: the mass system and the skeleton system (Norberg Schulz, 1968). He maintains that all regular-shaped forms consisting of a repetition of elements fall into these two categories of systems, the mass system and the skeleton system, while all others that do not have these properties are "amorphous." Norberg Schulz, the forms of skeletal systems characterise as "architectural" which provide ample opportunities of articulation, as well as repetitive properties and hierarchy, in opposed to the forms of the mass system which he terms as "sculptural". As a result, we should expect from the beautiful architecture that it attains its end most simply and naturally, avoids everything purposeless, and, following structural requirements, obtains the most remarkable regularity of its constituent forms and corresponding rationality in their proportions.

The relationship between form and architecture has provoked different contradictory approaches to modern architecture, from a return to historical models in postmodern discourse (Krier, 1988), to a rethinking of new situations within the radical pragmatism of contemporary architecture (BIG, 2009). In consideration of structural function and architectural form, Krier emphasises the need for their integration: 'Construction is closely related to function (Krier, 1988). A clearly defined concept of spatial organisation demands an appropriate structural solution. The more harmonious this unity, the closer one comes to the architectonic end product'. Schopenhauer's emphasis on structure, "of the necessary support to the given load" that depends on the building material, has anticipated modern thinking about construction.

On the opposite side are modern architectural practices such as BIG or MVRDV. Contrary to the classical avant-garde established by denying the existing, these new practices attempt to coexist with 
contradictions (BIG, 2009). "Rather than a revolution, we are interested in evolution," says Bjarke Ingels. And, instead of the slogan of classical modernism "less is better," he will say "yes is better". In this way the role of the architect is repositioned; from the pillar of the creation of the architectural form, he becomes a kind of "facilitator" or "manager" in the "negotiation" between very conflicting interests (MVRDV, 1998).

On the other hand, Frampton's rethinking of the modern architectural tradition points to the cultivation of the tectonic tradition as an essential element of the architectural form (Frampton, 1995). For Frampton redefining tectonics is a crucial question of how architecture is generated in the correlation of form, structure, function. In that sense, to establish this new position of production of the built environment, we should not necessarily return to the pre-industrial model, nor deviate from the poetic tectonics of architecture, but redefine the way of looking at architecture and structure through the dialogue of the architect and structural engineer.

\section{INTEGRATED STRUCTURAL DESIGN}

In the integrated design process, structural engineering design can be divided into three main stages: conceptual design, preliminary analysis and detailed analysis. For a given architectural form of a building, the choice of the optimal structure for the building is the most important mind creation of the structural engineer. The structural engineer should make recommendation and choice about the structural system, material criteria, identification of load path in the structure, vertical load resisting system, horizontal load restraining system, durability and safety of the structure, construction and maintenance and cost. Toady's approach in structural engineering is also related to the basic requirements related to the design of earthquake-resistant structures where a structural engineer should make decisions on:

- Basic principles of conceptual design: structural simplicity, uniformity, symmetry and redundancy, bi-directional resistance and stiffness, torsional resistance and stiffness, diaphragmatic behaviour at storey level and adequate foundation;

- Primary and secondary seismic members;

- Criteria for structural regularity in plane and elevation;

- Structural analysis;

- Safety verifications.

This contemporary approach for the structure by the structural engineer is nevertheless similar to the "philosophy of structures" proposed by the Torroja and Nervi $(1957,1956)$ nearly 65 years ago, which formulated a timeless set of design principles. These principles can be summarised as [1] Structure and architecture by Angus J. Macdonald:

- that a building or structure should perform its intended function well in every respect;

- that the structural form adopted for a building should be appropriate for the span and load involved;

- that the form should be appropriate for the material used;

- that the building or structure should be as simple to construct as possible;

- that the finished building or structure should be durable.

\section{CASE STUDY - INDIVIDUAL RESIDENTIAL BUILDING}

One of the most responsible and challenging design tasks for architects is designing a house for a particular household. The architect should possess excellent skills and knowledge to make habitats that should suit the needs of the users and future change of the structure of the same, given the extended life span of the houses. He should offer a concept of dwelling that would enable the modification of the interior space for the functional requirements of the next generations, without disturbing the aesthetic value and quality of the architectural form. 
The concept of integration of structural function with the architectural form, with all portions mutually interacting to achieve the full expression of architectural elements, will be considered on the example of an author's architectural project for an individual residential building.

Methodology / Structure and design process

Structure influences the design process through the selection of materials and a structural system suitable to the subdivision of the interior spaces. Flexibility and changeability on internal space are imperative in the approach of design for the structure. The first step in selecting structural system lies in the critical examination of the building's functions, the areas of its main subdivisions, the pattern of loading, and the vertical and horizontal functional connections required between the various parts of the building. The structure customises on subdividing the interior space; first, where the subdivided areas accommodate similar functions and are perceiving as being part of a larger space, and second, where structure separates different building functions, like circulation (stair and porch), from each other.

Based on a background of knowledge for structural theories, coupled with experience and intuition, leads the way for the selection of a structural system for the given example of an individual residential building. The initial structure of the plan consists of an orthogonal system of two-part and three-part intervals in the transverse and longitudinal direction $(2 \times 3)$. In the transverse direction, it is divided into two modules $a+a$. In the longitudinal direction, it is divided into three modules $a+b+$ $a$, with the last module consisting of two sub-modules $a=a 1+a 2$, so that the constructive line is in module a1. This conceptual framework regarding the circulation and distribution of the program is modified locally. The vertical structural elements consist of reinforced concrete columns and walls, with cross-sections that are reduced depending on the height of the plan. Horizontal structural elements include reinforced concrete peripheral beams and reinforced concrete slabs with integrated internal beams. Flat slab is a reinforced concrete slab supported directly by concrete columns without the use of beams. Flat slab is defined as one sided or two-sided support system with sheer load of the slab being concentrated on the supporting columns and a square slab called drop panels.

Orthogonal reinforced concrete simple flat slab structural system integrates well within the prismatic architectural form, under its permanence both defines and limits the activities within a structure, which represents space that we can call "generic space". The simple flat slab structural system is a particular case of a reinforced concrete frame (skeletal) structural system where columns directly support slabs. This structural system is generally susceptible to resistance to lateral loads. For that purpose, to improve the behaviour of the structural system, perimeter beams were designed combining the flat slab system with reinforced concrete shear walls making the closed core of reinforced concrete.

The extent of the physical presence of the structure, both in plans and cross-sections affects the degree of subtlety and clarity achieved in the interior space. The geometry, size and orientation of reinforced columns and shear walls, are designed to interpolate into the perimeter walls following the architectural form. This assimilation of the structural load-bearing elements with the fulfilled walls between them results in obtaining purity of interior spaces, which is difficult to achieve with this type of structural systems (figure 1). The floor plans are divided into two functional zones with the row of rectangular posts placed perpendicular to the longitudinal outer walls. This row of columns at the same time forms a narrow space, which we call the sub-functional, displaced between the other ones.

The access to the dwellings is a combination of the porch, stair and gallery, articulated in a semi-outdoor space exposing the program on the façade. The aesthetics of the mass relationship has been brought about by mightily cantilevering of the upper storey from the ground floor. The whole form is made from reinforced concrete merged with the load-bearing structure expressing the nature of the material on the façade. At the same time, the access entered into a new, structural alliance. The impact of concrete can be heightened by making it visible or perceptible. Architectural expression gives the permanent its own character. 

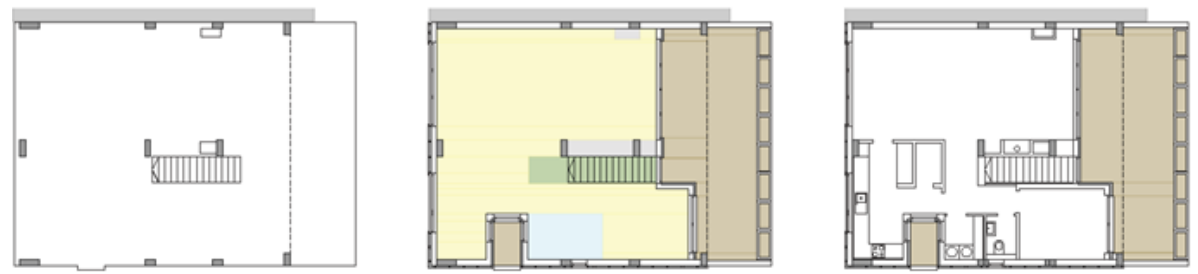

SECOND FLOOR PLAN
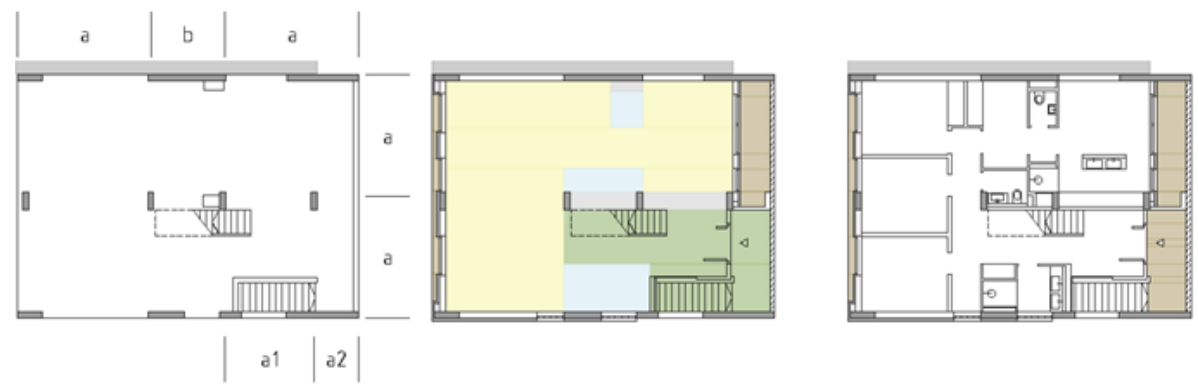

FIRST FLOOR PLAN

DWELLING UNIT "B"
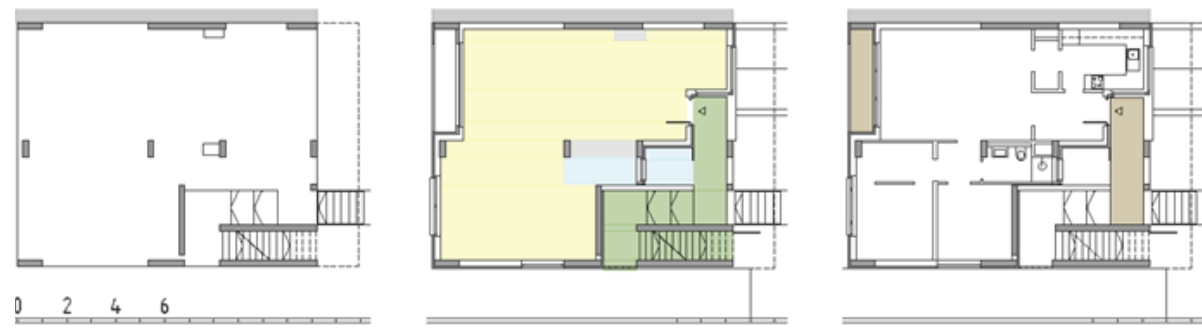

GROUND FLOOR PLAN

DWELLING UNIT "A"

ACCESS / COMMON AREA

LIVING AREA

TOLLETS

SERVICES

OUTDOR AREA

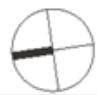

_ Figure 1: Floor plans to the individual residential house - synthesis of structural and architectural form

The integration of the structural function and the architectural form is analysing through a diagram of exploded views. Two different layers, Structure and Envelope, together form a framework as a "generic space" in which spatial arrangement takes place as a third layer called Scenery (figure 2). 


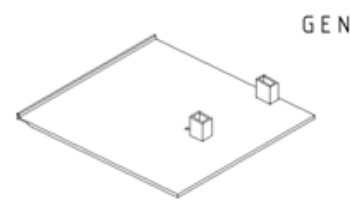

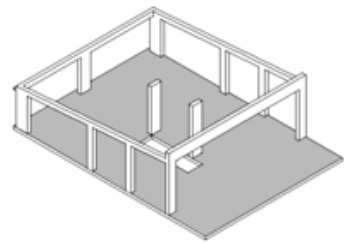

SECOND FLOOR PLAN

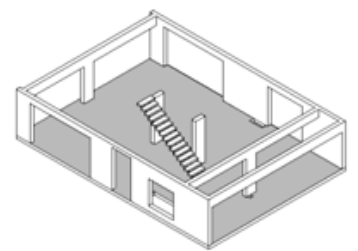

FIRST FLOOR PLAN

DWELLING UNIT "B"
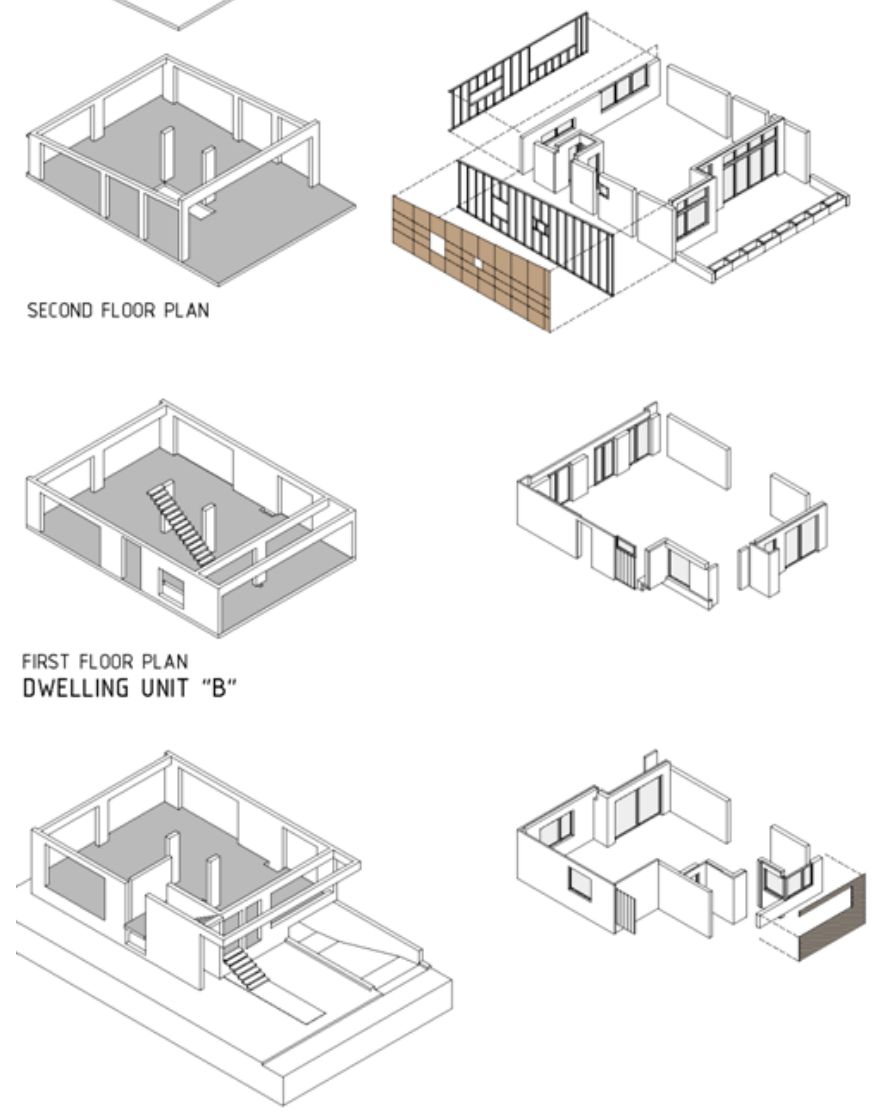

GROUND FLOOR PLAN

DWELLING UNIT "A"
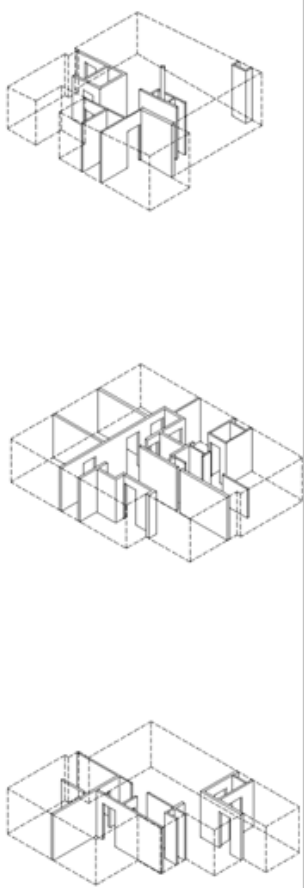

_ Figure 2: Decomposition, Exploded view of different layers of dwelling units

This example shows how architecture and structure create a homogeneous unit if the structural system is not an obstacle to perceive the work and the architectonic shape creates a logical structural solution.

\section{CONCLUSIONS}

The exploration of the relationship between architects and engineers can lead to a conclusion that three types are currently in play: architects who supported early modernism were interested in the tectonics of architectural buildings, which meant the inevitable close collaboration with engineers, and the engineer acted principally as the technician who ensured that it performed adequately in a 
technical sense (1); the emergence of individual engineers in whose works one can recognise high architectural qualities is also a feature of this period as a new concept of engineer/architect. Relationship occurs where the architect and the engineer is the same person (2); the third type of relationship between architects and engineers that of a genuinely collaborative partnership working in the design teams, establishing highly cooperative relationships and standard, re-emerged towards the end of the twentieth century. It has involved engineers and architects cooperating fully over the design process of a building. (3).

In this paper, we propose a framework for achieving a successful integration of architectural and structural design, to evolve an architecturally pleasing and structurally efficient building. In this context, the architect has a unique integrative role among and in the relations to conception and creation on physical wholes. Experience shows that as architects, we must possess a vast knowledge about the limitations and possibilities of concepts of structures related to their materiality. In other words, the skill of an innovative and creative approach in determining the structural performance of architectural forms, using the tectonic logic that reflects structures and materials. Finally, architects and structural engineers should take a more positive cooperative attitude during the design process from the beginning at the preliminary stage of conceptual design, where the conceptual idea as a more abstract in the next phases of development of the project documentation becomes more real. Architecture, as a successful creative product, can only be delivered within this process developed through the balance and harmony of all elements and actors as a whole.

\section{REFERENCES}

_ Frampton, Kenneth. 1995. Studies in Tectonic Culture: The Poetics of construction in Nineteenth and Twentieh Centry Architecture. Cambridge MA: The MIT Press

_ Ingels, Bjarke (BIG). 2009. Yes is More, An Archicomic on Architectural Evolution. Koln: EVERGRIN GmbH.

_ Korab-Karpowicz, W. 2011. Schopenhauer's Theory of Architecture. DO-10.1002/9781444347579.ch12

_ Krier, Rob. 1988. Architectural Composition. Academy Editions, Rizzoli, p. 27.

_ Leupen, Bernard. 2006. Frame and Generic Space. Rotterdam: 010 Publishers.

- Macdonald, Angus. 1997. Structural Design for Architecture. Oxford: Architectural Press.

- Macdonald, Angus. 2001. Structure and Architecture. 2st ed. Oxford: Architectural Press.

_ MVRDV, 1998. FARMAX, Excursions on Density. Rotterdam: 010 publishers.

_ Norberg -Schulz, Christian. 1968. Intentions in Architecture. The MIT Press.

- Rappoport, Amos.1969. House Form and Culture. Englowood Cliffs, N.J.: Prentice-Hall, Inc. 